\title{
Neuroimaging abnormalities, neurocognitive function, and fatigue in patients with hepatitis $\mathrm{C}$
}

OPEN

April D. Thames, PhD Steven A. Castellon, PhD Elyse J. Singer, MD

Rajakumar Nagarajan, $\mathrm{PhD}$

Manoj K. Sarma, PhD Jason Smith, PharmD Nicholas S. Thaler, PhD Jonathan Hien Truong, $\mathrm{MD}$

Daniel Schonfeld, BS M. Albert Thomas, PhD Charles H. Hinkin, PhD

Correspondence to Dr. Thames: athames@mednet.ucla.edu

Supplemental data at Neurology.org/nn

\section{ABSTRACT}

Objective: This study examined neurologic abnormalities (as measured by proton magnetic resonance spectroscopy imaging and diffusion tensor imaging), neurocognitive performance, and fatigue among a sample of adults with hepatitis $\mathrm{C}$ virus (HCV). We hypothesized that $\mathrm{HCV}+$ individuals would demonstrate structural brain abnormalities and neurocognitive compromise consistent with frontostriatal dysfunction as well as increased fatigue compared to controls.

Method: Participants were 76 individuals diagnosed with $\mathrm{HCV}$ and 20 controls who underwent a comprehensive neurocognitive evaluation and clinical assessments. A subset of the $\mathrm{HCV}+$ participants ( $n=29$ ) and all controls underwent MRI.

Results: Individuals diagnosed with chronic HCV infection demonstrated greater fractional anisotropy in the striatum as well as greater mean diffusivity in the fronto-occiptal fasciculus and external capsule compared to HCV - controls. HCV + participants also demonstrated lower levels of $\mathrm{N}$-acetylaspartate in bilateral parietal white matter and elevations in myo-inosital (ml) in bilateral frontal white matter compared to $\mathrm{HCV}$ - controls (all $p$ values $<0.05$ ). HCV+ participants also demonstrated significantly poorer neuropsychological performance, particularly in processing speed and verbal fluency. HCV+ patients reported higher levels of fatigue than controls, and fatigue was significantly correlated with diffusivity in the superior fronto-occipital fasciculus, elevations in $\mathrm{ml}$ in frontal white matter, and overall cognitive performance.

Conclusions: Our results suggest that HCV-associated neurologic complications disrupt frontostriatal structures, which may result in increased fatigue and poorer cognitive performance, particularly in those cognitive domains regulated by frontostriatal regions. Neurol Neuroimmunol Neuroinflamm 2015;2:e59; doi: 10.1212/NXI.0000000000000059

\section{GLOSSARY}

ANOVA = analysis of variance; CRLB = Cramer-Rao lower bound; DTI = diffusion tensor imaging; $\mathbf{F A}=$ fractional anisotropy; FDR = false discovery rate; FOV = field of view; HCV = hepatitis C virus; H-MRS = proton $\mathrm{H}$ magnetic resonance spectroscopy; MD = mean diffusivity; MELD = Model for End-Stage Liver Disease; $\mathbf{m l}=$ myo-inosital; $\mathbf{M R S I}=$ proton magnetic resonance spectroscopy imaging; NAA $=\mathrm{N}$-acetylaspartate; PRESS $=$ point-resolved spectroscopy; TE $=$ echo time; TR $=$ repetition time; VAS $=$ Visual Analogue Scale; VOI = volume of interest; WAIS-III = Wechsler Adult Intelligence Scale-Third Edition.

In the United States, approximately 3.2 million people have hepatitis $\mathrm{C}$ virus (HCV), with chronic infection in nearly $75 \%-85 \%$ of cases. ${ }^{1} \mathrm{HCV}$ is thought to cross the blood-brain barrier primarily by infecting surrounding monocytes and progenitor cells. ${ }^{2,3}$ Consequently, studies have documented neurologic abnormalities and cognitive impairments among HCV+ individuals without advanced liver disease. ${ }^{4,5}$

Studies using proton $\mathrm{H}$ magnetic resonance spectroscopy (H-MRS) have demonstrated lower levels of $N$-acetylaspartate (NAA) in frontal white matter and increases in myo-inosital (mI) and choline/creatine values in the basal ganglia. ${ }^{6-8}$ In a few studies that used diffusion tensor imaging (DTI), patients with HCV demonstrated lower fractional anisotropy (FA) in the inferior

From the David Geffen School of Medicine (A.D.T., S.A.C., E.J.S., R.N., M.K.S., N.S.T., M.A.T., C.H.H.), University of California, Los Angeles; Greater Los Angeles VA Healthcare System (S.A.C., J.S., D.S., C.H.H.); and Department of Infectious Disease (J.H.T.), Kaiser Permanente Antelope Valley, Lancaster, CA.

Go to Neurology.org/nn for full disclosures. Funding information and disclosures deemed relevant by the authors, if any, are provided at the end of the article. The Article Processing Charge was paid by the University of California, Los Angeles.

This is an open access article distributed under the terms of the Creative Commons Attribution-Noncommercial No Derivative 3.0 License, which permits downloading and sharing the work provided it is properly cited. The work cannot be changed in any way or used commercially. 
fasciculus, the inferior fronto-occipital fasciculus, and the genu of the corpus callosum compared to normal controls. ${ }^{9,10}$

Neurocognitive studies have found that $\mathrm{HCV}$-infected individuals demonstrate increased neurocognitive dysfunction compared to controls. ${ }^{5,11-14}$ Selective deficits in attention, concentration, and psychomotor speed are most commonly reported across studies, ${ }^{4,5,15,16}$ and these deficits are largely independent of such factors as liver fibrosis.

In addition to cognitive dysfunction, approximately $65 \%-80 \%$ of chronically infected patients complain of fatigue that is independent of liver dysfunction. ${ }^{17}$ In a study of HCV+ patients, moderate fatigue was associated with poorer cognitive performance and reduced EEG brain activity compared to $\mathrm{HCV}+$ patients with mild fatigue. ${ }^{8}$ Fatigue and cognitive dysfunction may share overlapping pathophysiologic mechanisms; however, very few studies have had sufficiently large samples to examine neurocognitive abnormalities and fatigue in tandem. Therefore, the objective of this study was to examine neuroimaging abnormalities (H-MRS and DTI), neurocognitive performance, and fatigue among a sample of $\mathrm{HCV}+$ patients.

METHODS Our initial sample consisted of $87 \mathrm{HCV}+$ participants who were recruited from several hepatology clinics and infectious disease clinics located throughout the greater Los Angeles catchment area. Controls $(\mathrm{n}=21)$ were recruited from the community through advertisements and flyers.

Standard protocol approvals, registrations, and patient consents. All procedures received prior approval by the University of California, Los Angeles and VA Greater Los Angeles Healthcare System Institutional Review Board Committees for studies involving human subjects. All HCV+ patients participating in this study met clinical criteria for initiating HCV therapy but had not yet begun treatment. All data reported in the current study were collected at participants' baseline visit. As part of procedures outlined in the parent study, a nested cohort of $\mathrm{HCV}+$ participants underwent neuroimaging $(\mathrm{n}=29)$. There were no statistically significant differences between $\mathrm{HCV}+$ participants who underwent neuroimaging and those who did not on key demographic variables such as age, sex, ethnicity, past drug abuse, current drug use, Model for End-Stage Liver Disease (MELD) score, and psychiatric functioning (all $p$ values $>$ $0.05)$. All participants provided informed consent prior to undergoing procedures. Inclusion criteria were as follows: (1) 18 years of age, (2) able to read and write in English, (3) and completed at least 6th grade education. Exclusion criteria were as follows: (1) decompensated cirrhosis/liver failure (detected by blood tests or liver biopsy) with MELD scores $>12$; (2) current or past psychotic spectrum disorder; (3) significant depression as judged by the study psychiatrists/psychologists (defined as current moderate or severe major depressive disorder) or suicidal ideation (factors that were controlled for initiating interferon treatment); (4) history of learning disability, seizure disorder, closed-head injury with loss of consciousness in excess of 30 minutes, or any other neurologic disease; (5) evidence of any other CNS opportunistic infection or neoplasm; (6) hepatitis B infection; (7) diagnosis of HIV infection as evidenced by HIV antibody testing; (8) recent illicit drug use (confirmed by urine toxicology); and (9) contraindications for MRI (for the nested cohort who underwent neuroimaging). After applying exclusion criteria, our final sample (those eligible for analysis) included $76 \mathrm{HCV}+$ participants and 20 controls. (See supplementary table e-1 for clinical characteristics of the HCV+ sample.) Ten HCV+ participants were determined to be ineligible due to liver cirrhosis, and 1 control participant tested positive for stimulants at study visit.

Brain MRI was performed using a 3-tesla Trio MRI scanner (Siemens Medical System, Erlangen, Germany). High-resolution MRI included T1-weighted images using a magnetizationprepared rapid acquisition gradient-echo sequence using the following parameters: repetition time (TR)/echo time (TE) $=2,220 / 2.2$ msec, inversion time $=900 \mathrm{msec}$, average $=1$, matrix size $=256 \times$ 256 , field of view $(\mathrm{FOV})=240 \times 240 \mathrm{~mm}^{2}$, slice thickness $=$ $1 \mathrm{~mm}$, number of slices $=176$. DTI was acquired using a singleshot echo planar dual spin echo sequence with ramp sampling. The b-factor was set to $1,000 \mathrm{~s} / \mathrm{mm}^{2}$, TR $=9,600 \mathrm{msec}$, TE $=90$ msec, flip angle $=90^{\circ}$, and averages $=1$. A total of 71 axial sections were acquired using an image matrix of $130 \times 130$, a slice thickness of $2 \mathrm{~mm}$ with no interslice gap, and an FOV of $256 \times$ $256 \mathrm{~mm}^{2}$.

Proton spectra were collected using the $2 \mathrm{D}$ proton magnetic resonance spectroscopy imaging (MRSI) technique with the volume of interest (VOI) preselected by means of point-resolved spectroscopy (PRESS). Volume-selective 2D MRSI was performed on a $20-\mathrm{mm}$ slab superior to the ventricles with TE of $30 \mathrm{msec}$ and TR of $2,000 \mathrm{msec}$. The nominal voxel size was $2.82 \mathrm{~cm}^{3}\left(16 \times 16\right.$ phase encode steps over an $18 \times 20 \mathrm{~cm}^{2}$ FOV). Outer-volume saturation bands were applied to all 6 sides of the VOI localized by the PRESS sequence to suppress the lipid contamination.

Participants completed a comprehensive neuropsychology test battery. We assessed attention using the Wechsler Adult Intelligence Scale-Third Edition (WAIS-III) Letter-Number Sequencing subtest ${ }^{18}$ and the Paced Auditory Serial Addition Test (only the first 50 trials $^{19}$; processing speed using the WAIS-III Digit Symbol and Symbol Search subtests, ${ }^{18}$ Trail Making Test Part A, ${ }^{20}$ and Stroop color naming and word reading ${ }^{21}$; learning and memory using the Hopkins Verbal Learning Test-Revised ${ }^{22}$ and the Brief Visuospatial Memory Test-Revised ${ }^{23}$; verbal/language fluency using the Controlled Oral Word Association Test, ${ }^{24}$ executive functioning using Trail Making Test Part B and Stroop color-word interference test ${ }^{20,21}$; and motor speed using the Grooved Pegboard test. ${ }^{25}$ Raw scores were converted into demographically adjusted $t$ scores, grouped by neurocognitive domain, and averaged to create domain $t$ scores. A global neurocognition score was calculated by averaging $t$ scores from individual neuropsychological tests.

Fatigue was assessed with the Visual Analogue Scale $\left(\mathrm{VAS}^{26}\right)$. The VAS contains 18 visual analogue lines with bipolar anchors with descriptors relating to energy and fatigue. Participants are asked to place a mark between the anchors. Internal consistency of the VAS in our sample was high (Cronbach $\alpha=0.86$ ). The total score from the VAS-Fatigue subscale was examined in the current study.

DTI and MRSI postprocessing. DtiStudio was used to create FA and mean diffusivity (MD) maps. We used RoiEditor for 
preprocessing procedures according to a modified version of the active contour method ${ }^{27}$ and DiffeoMap. Images were applied to the JHU-MNI-SS template. Dual-contrast large deformation diffeomorphic metric mapping was used for nonlinear transformations. White matter parcellation map was used to segment the brain into 130 regions based on anatomical labeling, which included both the gray and white matter. Once these regions were extracted, the cortex and the surrounding white matter were segmented using an FA threshold of $\geq 0.25$. We focused our analyses on regions of the corona radiata, insula, internal capsule, external capsule, striatum, fronto-occiptial fasciculus, cingulum, thalamus, hippocampus, and amygdala based on prior studies. .,10,28,29 $^{2}$

For MRSI, metabolites were quantitated in each voxel using the frequency-domain fitting routine called LC-Model algorithm, which analyzes the in vivo brain spectrum as a linear combination of individual simulated metabolite spectra that constitute the basis set or prior knowledge. ${ }^{30}$ We were able to quantify total NAA_NAAG (NAA + NAA glutamate), total choline (GPC_Pch), mI, and glutamate/glutamine (Glu_Gln) for regions of frontal white and gray matter, parietal white and gray matter, and basal ganglia (see figure 2). The metabolite ratios were normalized with respect to creatine (3.09 ppm). The accuracy of the quantitation was characterized using Cramer-Rao lower bound (CRLB), and metabolite ratios with CRLB $<30 \%$ were considered for further analysis.

Preliminary analyses. Demographic characteristics are presented in table. No statistically significant differences were found for potential confounding variables such as age, years of education, ethnicity, and estimated premorbid functioning (as measured by the Wechsler Test of Adult Reading) (all $p$ values $>0.05$ ). Groups also did not differ in current drug use. Between-groups analysis of variance (ANOVA) was used to examine differences between $\mathrm{HCV}$ and control groups on our 31 outcome variables of interest: neuroimaging (23 variables), neurocognitive assessment (7 variables), and fatigue (1 variable). Outcome variables were all analyzed on a continuous scale and assumptions for performing ANOVA and Pearson correlations were checked prior to running analyses. Next, DTI and MRSI variables were correlated with neurocognitive performance and fatigue.

We used the false discovery rate (FDR) ${ }^{31}$ to correct for multiple comparisons with our outcome measures. FDR is sometimes preferred over family-wise error rate methods (e.g., Bonferroni) because it provides greater statistical power and reduces the chance of making type II errors.

Sensitivity analysis was performed using G*Power version 3.1. Given our available sample size of 96 for the neurocognitive and fatigue data, adjusted $\alpha$ level of 0.01 (for multiple comparisons), and power of 0.80 , we had enough power to detect medium effects $(f=0.31)$. This is consistent with effect sizes reported in previous investigations that have examined neurocognitive differences between $\mathrm{HCV}+$ patients and controls. ${ }^{4,8,17}$ For neuroimaging analyses, with a sample of 49 , we had enough power to detect medium to large effects. This is also consistent with the effect sizes reported by neuroimaging studies that have compared $\mathrm{HCV}+$ patients to controls. ${ }^{12,17}$

RESULTS DTI. There were statistically significant group differences in $\mathrm{FA}$ in the striatum $\left(F_{1,48}=8.49\right.$, $p<0.005)$, with the HCV group demonstrating higher FA levels than controls. While group differences in FA in the thalamus $\left(F_{1,48}=4.6, p=0.04\right)$ and insula $\left(F_{1,48}=\right.$ $3.86, p=0.05)$ emerged, these did not survive multiple comparisons correction. There were no statistically significant group differences in FA values among our other brain regions of interest (see figure 1A and table e-2).

Among the HCV+ group, higher levels of FA in the striatum were correlated with poorer overall neuropsychological performance $\left(r_{29}=-0.45, p=0.01\right.$; $\left.r_{29}=-0.53, p=0.003\right)$ and the domain of language fluency $\left(r_{29}=-0.41, p=0.02\right)$.

Individuals with chronic HCV infection demonstrated greater $\mathrm{MD}$ in the fronto-occiptal fasciculus $\left(F_{1,48}=18.6, p<0.0001\right)$ and external capsule $\left(F_{1,48}=10.8, p=0.002\right)$ than controls (see figure $1 \mathrm{~B})$. There was a statistical trend toward group MD differences in the insula $\left(F_{1,48}=3.86, p=0.05\right)$; however, this did not survive correction for multiple comparisons. There were no statistically significant relationships between MD in our regions of interest and neurocognitive performance.

MRSI. HCV + participants demonstrated lower levels of NAA in bilateral parietal white matter $\left(F_{1,48}=\right.$ 5.37, $p=0.02$ ) and elevations of $\mathrm{mI}$ in bilateral frontal white matter $\left(F_{1,48}=9.48, p=0.004\right)$ compared to controls (see figure 3 and table e-3). For the $\mathrm{HCV}+$ group, greater levels of frontal white matter $\mathrm{mI}$ were significantly correlated with poorer cognitive performance in the domains of processing speed $\left(r_{29}=-0.43, p=0.02\right)$ and verbal/language fluency $\left(r_{29}=-0.41, p=0.007\right)$. No other MRSI regions of interest correlated with neurocognitive performance. Higher NAA in bilateral parietal

\section{Figure 1 MRSI regions of interest}

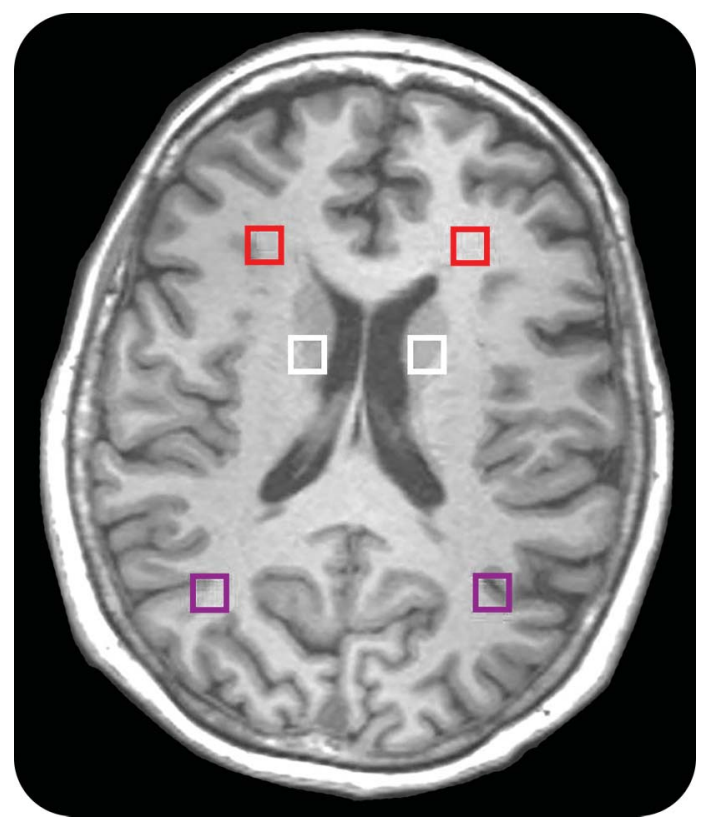

Proton magnetic resonance spectroscopy imaging (MRSI) regions of interest of frontal white, parietal white, and basal ganglia. 


\begin{tabular}{|c|c|c|c|c|}
\hline & $\begin{array}{l}\text { Hepatitis } \mathrm{C} \text { group }(n=76) \\
\text { Mean/percentage }(\mathrm{SD})\end{array}$ & $\begin{array}{l}\text { Control group }(n=20) \\
\text { Mean/percentage (SD) }\end{array}$ & $F / \chi^{2}$ & p \\
\hline \multicolumn{5}{|l|}{ Demographics } \\
\hline Age, y & $56.7(5.5)$ & $54.4(5.5)$ & 2.61 & 0.11 \\
\hline Education, y & $13.0(2.2)$ & $13.6(1.7)$ & 1.43 & 0.23 \\
\hline Sex, \% male & 78.5 & 50.0 & 8.23 & $<0.01$ \\
\hline Ethnicity & & & 2.46 & 0.78 \\
\hline$\%$ Caucasian & 51.6 & 42.3 & & \\
\hline$\%$ African American & 29.0 & 34.5 & & \\
\hline$\%$ Latino & 15.1 & 23.1 & & \\
\hline$\%$ Asian/Pacific Islander & 2.2 & 0.0 & & \\
\hline$\%$ American Indian & 1.1 & 0.0 & & \\
\hline$\%$ Other & 1.1 & 0.0 & & \\
\hline Estimated IQ & 98.5 (11.2) & $101.7(10.5)$ & 1.69 & 0.20 \\
\hline VAS-F subscale & $30.8(24.9)$ & $19.0(15.3)$ & 5.21 & 0.02 \\
\hline \multicolumn{5}{|c|}{ Positive drug screening, active use } \\
\hline$\%$ Amphetamines & 0.0 & 0.0 & NA & \\
\hline$\%$ Barbiturates & 0.0 & 1.2 & 0.31 & 0.58 \\
\hline \% Benzodiazepines & 0.0 & 8.5 & 2.28 & 0.13 \\
\hline$\%$ Cocaine & 0.0 & 0.0 & NA & \\
\hline \% Marijuana & 8.0 & 11.0 & 0.18 & 0.67 \\
\hline$\%$ Opiates & 0.0 & 3.7 & 0.94 & 0.33 \\
\hline
\end{tabular}

Abbreviation: VAS-F $=$ Visual Analogue Scale-Fatigue.

white matter was significantly correlated with lower diffusivity in the fronto-occipital fasciculus $\left(r_{29}=\right.$ $-0.36, p=0.02$ ), whereas greater levels of frontal white matter $\mathrm{mI}$ were significantly correlated with higher diffusivity in the fronto-occipital fasciculus $\left(r_{29}=0.47, p=0.01\right)$.

Neurocognition. HCV-infected individuals demonstrated poorer overall neurocognitive performance than controls $\left(F_{1,94}=5.6, p=0.02\right)$. Cognitive domains that contributed to global findings included reduced processing speed $\left(F_{1,94}=3.91, p=0.04\right)$ and verbal fluency $\left(F_{1,94}=8.52, p=0.005\right)$ (see figure 4$)$.

Fatigue. As expected, $\mathrm{HCV}+$ participants reported greater fatigue $\left(F_{1,94}=7.41, p=0.008\right)$ than controls. Among the $\mathrm{HCV}+$ group, fatigue was not correlated with any of the DTI regions (all $p$ values $>0.05$ ). Higher fatigue scores correlated with higher levels of $\mathrm{mI}$ in frontal white matter $\left(r_{29}=0.53, p<0.01\right)$. Among HCV+ patients, higher fatigue scores correlated with poorer overall neurocognitive performance $\left(r_{75}=-0.36, p<\right.$ $0.001)$ and domains of attention $\left(r_{75}=-0.26, p=\right.$ $0.01)$, processing speed $\left(r_{75}=-0.31, p=0.002\right)$, and executive functioning $\left(r_{75}=-0.40, p<0.001\right)$. There was no statistically significant correlation between fatigue and motor functioning.
DISCUSSION The current study examined the effects of chronic HCV infection on microstructural brain abnormalities, cerebral metabolites, fatigue, and neurocognitive performance. Major strengths of the current investigation include the use of DTI and MRSI in combination with measures of neurocognitive functioning and fatigue, and the use of a control group for comparison. As hypothesized based on prior literature, we observed microstructural abnormalities in such areas as the striatum, external capsule, and fronto-occipital fasciculus, which is consistent with previous DTI studies of $\mathrm{HCV}^{9,10}$ and findings among individuals with HIV infection. ${ }^{28,29}$

We observed greater FA in gray matter regions of the striatum in $\mathrm{HCV}+$ patients compared to healthy volunteers. Higher FA in the striatum has been found among patients with Huntington disease ${ }^{32}$ and is thought to be due to degeneration of efferent pathways that increase the coherence of gray matter structures. In a study of patients with chronic subdural hematoma, increased FA was found in the striatum, which reduced following surgical intervention. ${ }^{33}$ Therefore, our findings are consistent with other investigations of neuropathology in regions that are affected in HCV.

Increased diffusivity in the fronto-occipital tract and external capsule was also found in the HCV+ group 
A. DTI FA values between the hepatitis $\mathrm{C}$ group and controls

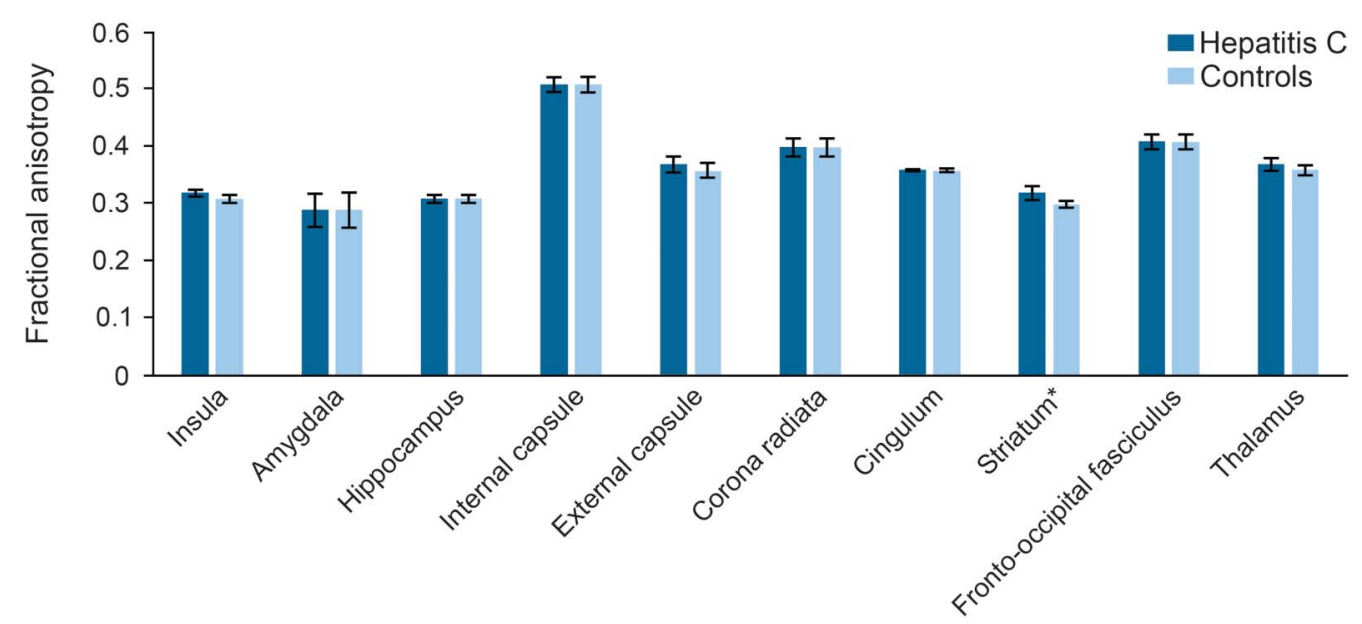

B. DTI diffusion values between the hepatitis $\mathrm{C}$ group and controls

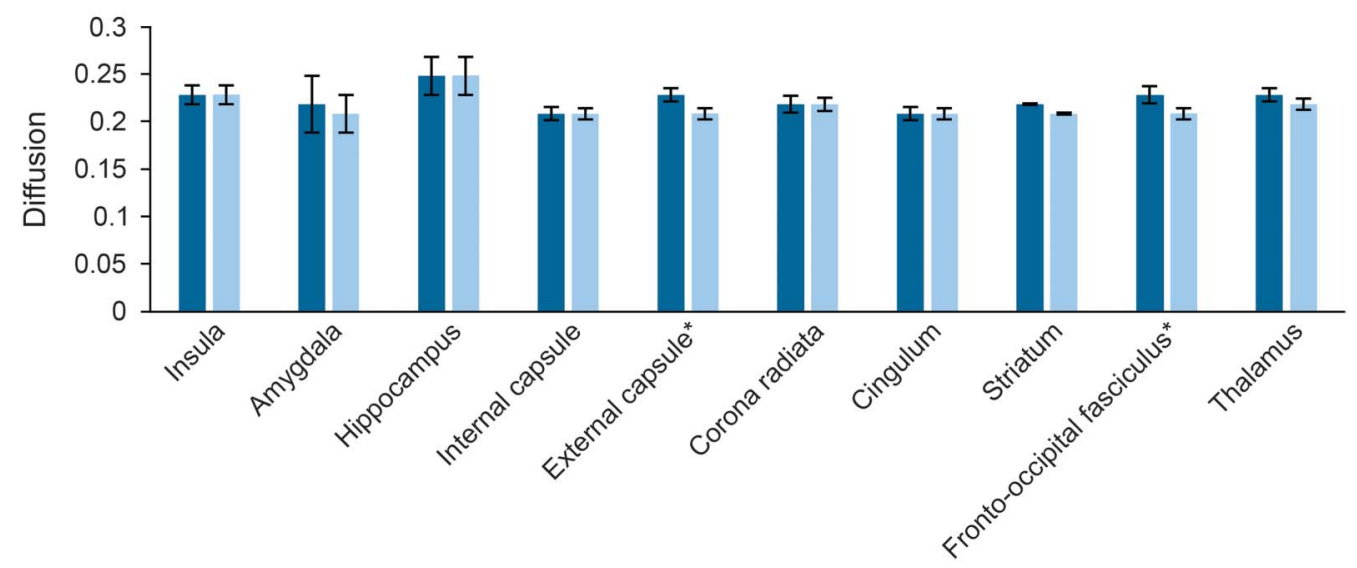

(A) DTI FA values, (B) DTI diffusion values. *Statistically significant at FDR-adjusted $p$ value. DTI = diffusion tensor imaging; $F A=$ fractional anisotropy; FDR $=$ false discovery rate.

compared to controls. The fronto-occipital tract has been suggested as modulating frontal lobe-related inhibitory control and occipital lobe-related sensory inputs. ${ }^{34}$ Alterations of this tract may interfere with integrating sensory information and inhibiting control over impulses and emotion, which is problematic among drug abusers. The external capsule contains a variety of different nerve bundles and pathways connecting the cerebral cortex to subcortical nuclei as well as connecting different parts of the cortex to each other. Therefore, disruption to fibers of the external capsule may result in dysfunction of frontal-subcortical circuitry.

$\mathrm{HCV}+$ participants demonstrated lower levels of NAA in bilateral parietal white matter and elevations of $\mathrm{mI}$ in bilateral frontal white matter compared to controls, which was associated with poorer performance in the cognitive domains of processing speed and verbal/language fluency. Further, there was a correspondence between our DTI and MRSI measures. Specifically, higher NAA in parietal white matter was significantly correlated with lower diffusivity in the fronto-occipital fasciculus, whereas greater frontal white matter $\mathrm{mI}$ was significantly correlated with higher diffusivity in the fronto-occipital fasciculus.

That stated, our MRSI results were generally consistent with previous MRSI studies of HCV + cohorts, ${ }^{8,12,35}$ although we did not observe abnormal cerebral metabolite levels in basal ganglia as was expected.

However, in the current study we were careful to exclude participants with medical (e.g., cirrhosis) and psychiatric conditions that potentially could have confounded interpretation of the neuroimaging findings. Through this process we may have excluded $\mathrm{HCV}+$ individuals with more severe neurologic impairments and neuropathologic changes in subcortical structures that are detectable by H-MRS. Although $\mathrm{HCV}+$ patients demonstrated poorer global neurocognitive performance than controls, examination of performance data suggests normal range of performance (i.e., $T>40$ ). Again, because of the use of 


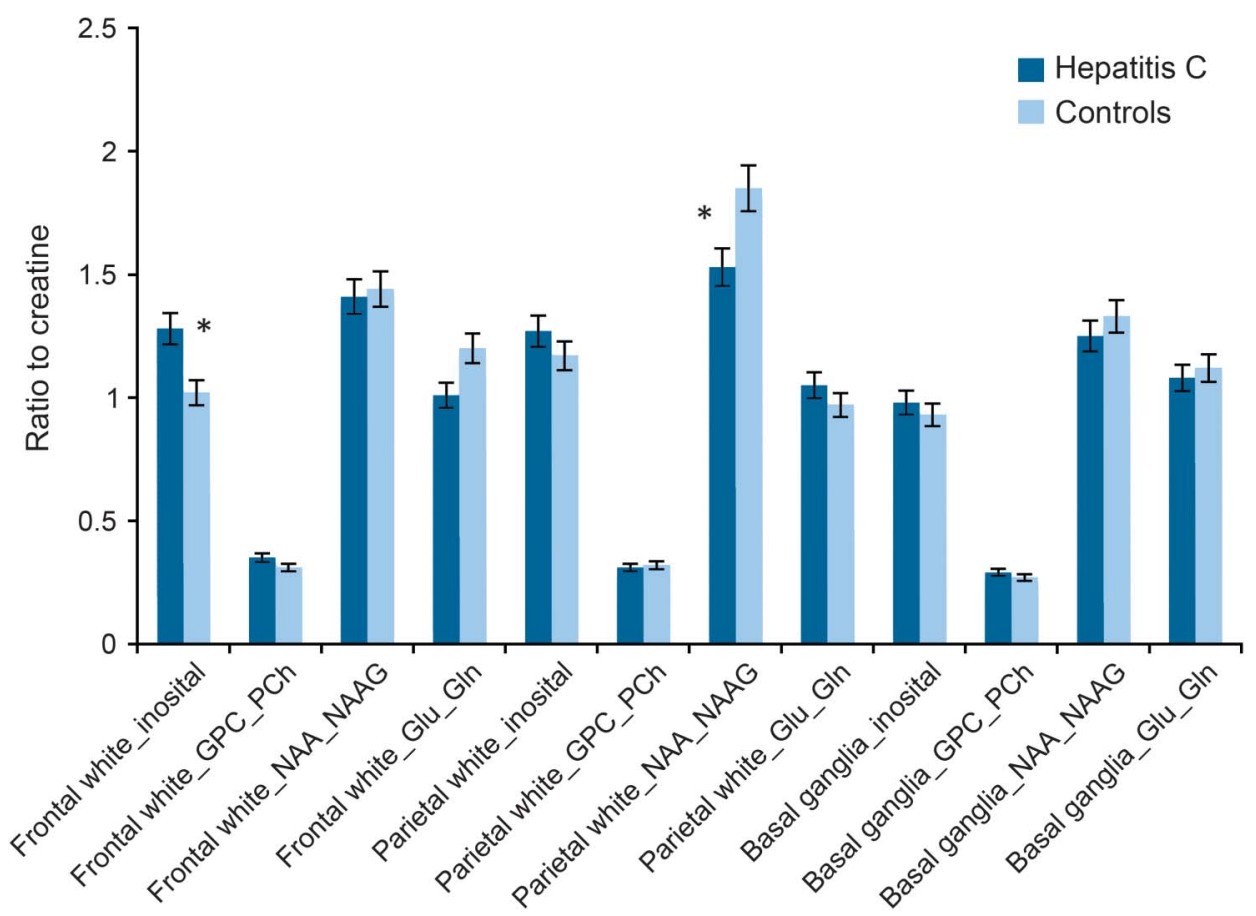

Glu_Gln = glutamate + glutamine; GPC_Pch = gylcerophosphocholine + phosphocholine (total choline); MRSI = proton magnetic resonance spectroscopy imaging; NAA_NAAG $=\mathrm{N}$-acetylaspertate $+\mathrm{N}$-acetylaspartate glutamate. $*=$ Statistically significant at FDR-adjusted $p$ value.

stringent inclusion/exclusion criteria, this group may not be fully representative of the general HCV+ population. Despite the potential recruitment of higherfunctioning HCV+ individuals, we still found the poorer performance in the cognitive domains of processing speed and verbal fluency (relative to controls)

Figure 4 Neurocognitive performance differences

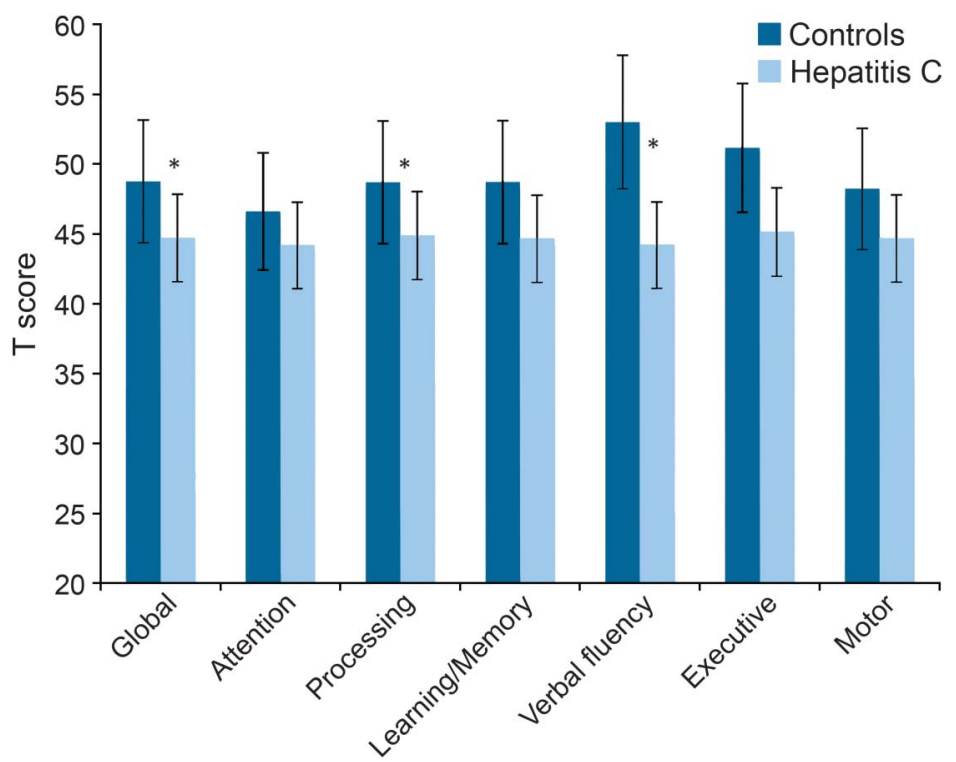

Neurocognitive performance differences between the hepatitis $C$ group and controls. $*=$ Statistically significant at FDR-adjusted $p$ value. that has been reported across other studies, ${ }^{4,5,13,15,16}$ and this performance was independent of such factors as liver fibrosis and history of substance abuse.

$\mathrm{HCV}+$ participants also reported greater fatigue than controls, which was associated with abnormalities in frontal white matter, whereas poorer cognitive performance was associated with abnormalities in both frontal white matter and subcortical structures. These results suggest that HCV-associated neurologic complications that are specific to changes in frontal-subcortical structures give rise to both reduced cognitive performance and fatigue. The specific cognitive deficits observed in verbal/language fluency and information processing speed are all regulated by frontal-striatal structures. ${ }^{36}$ In our sample, verbal fluency demonstrated the greatest degree of performance difference between $\mathrm{HCV}+$ and control groups and the strongest correlation with elevated levels of $\mathrm{mI}$ in frontal white matter.

There are limitations to the current study. First, while structural neuroimaging methods are helpful in identifying microstructural pathology that may not be detected on standard MRI, they do not provide a clear understanding about the functions of these neural circuits. Hence, existing disruptions in a neural circuit may make a patient more vulnerable to developing symptoms such as fatigue. Second, although we attempted to control for a number of demographic variables between HCV patients and controls, we recognize that there are a myriad of 
psychosocial differences (e.g., stress, past drug use) that may account for the reduced cognitive performance and structural brain differences that were observed in the current study. For instance, we were unable to examine past drug abuse differences between our $\mathrm{HCV}+$ and control groups because information on past drug abuse was not collected from the controls. We recognize that in order to precisely rule out the effects of past drug abuse we would have needed to recruit a sample of past drug abusers who were HCV-. However, considering that $61 \%$ of our $\mathrm{HCV}+$ patients reported a lifetime history of cocaine or opiate use, we attempted to address this concern by examining the effects of past drug abuse within this subgroup. While we did not find significant differences in our neuroimaging or neurocognitive data as a function of past drug abuse (all $p$ values $>0.10$ ), we cannot rule out the residual confounding effects of distant substance use on neurologic function.

Despite these limitations, the current study represents a significant extension of the extant literature on HCV's effects on neurologic and neurobehavioral functioning by demonstrating how abnormalities in frontal/parietal and subcortical structures have independent and overlapping relationships with cognitive performance and fatigue.

It has long been known that HCV is hepatotoxic; increasingly there is reason to believe that it is neurotoxic as well. While the precise pathophysiologic mechanism remains unclear, findings from the current study as well as others have demonstrated that $\mathrm{HCV}$ infection is associated with neurophysiologic and neurobehavioral abnormality. While advances in the pharmacologic treatment of HCV hold incredible promise, there remain millions of $\mathrm{HCV}$-infected adults in the United States and approximately 100 million worldwide. Continued study of the neurologic effects of HCV is needed.

\section{AUTHOR CONTRIBUTIONS}

Dr. Thames was involved in the study design, was responsible for conducting statistical analyses of study hypotheses, assisted with processing of neuroimaging data, and drafted the initial version of the manuscript. Dr. Castellon was involved in the conceptualization of the parent study; provided scientific input on study design, data collection, and interpretation; provided consultation for statistical analyses in the current study; provided critical revisions to the write-up of study findings; and gave final approval of the manuscript for submission. Dr. Singer was involved in the conceptualization of the parent study design, provided scientific input on clinical and medical data collection and interpretation, provided critical revisions to the write-up of study findings, and gave final approval of the manuscript for submission. Dr. Nagarajan was involved in the study design of the MR spectroscopy data acquisition and MR spectroscopy postprocessing, provided critical revisions to the write-up of MR spectroscopy findings and interpretation, and gave final approval of the manuscript for submission. Dr. Sarma was involved in the study design of the diffusion tensor imaging data acquisition and processing, assisted with the analyses, provided critical revisions to the write-up of diffusion tensor imaging findings and interpretation, and gave final approval of the manuscript for submission. Dr. Smith was involved in the interpretation of clinical data, provided critical revisions to the manuscript draft, and gave final approval of the manuscript for submission. Dr. Thaler assisted with statistical analyses of the neuropsychological data, assisted with the writeup of results, provided critical revisions to manuscript drafts, and gave final approval of the manuscript for submission. Dr. Truong provided scientific input on medical data acquisition, provided critical revisions to the manuscript draft, and gave final approval of the manuscript for submission. Mr. Schonfeld was involved in data acquisition, formatted the tables and figures, assisted with the write-up of the methods for the manuscript, and gave final approval of the manuscript for submission. Dr. Thomas was responsible for the conceptualization and study design of the neuroimaging data, provided scientific input on sequence parameters and data analysis, provided critical revisions to manuscript drafts, and gave final approval of the manuscript for submission. Dr. Hinkin is the PI of the parent project and was responsible for the conceptualization of the study design, provided scientific oversight for all study phases, provided critical portions of manuscript drafts, and gave final approval of the manuscript for submission.

\section{STUDY FUNDING}

Funding support for the current study was provided through the NIH (RO1MH083553, PI: C.H. Hinkin).

\section{DISCLOSURE}

A.D. Thames has received research support from the NIMH and the American Psychological Association Society for Clinical Neuropsychology. S.A. Castellon reports no disclosures. E. Singer is on the NIH study section advisory board, is a reviewer for ORAU grants, and receives funding from NIMH, MINDS, and NIDA. R. Nagarajan, M.K. Sarma, and J. Smith report no disclosures. N.S. Thaler received research support from the NIH. J.H. Truong and D. Schonfeld report no disclosures. M.A. Thomas has received research support from NIH and CDMRP-Prostate Cancer Research Program. C.H. Hinkin has received research support from NIH and from a VA Merit Review Grant. Go to Neurology.org/nn for full disclosures.

Received July 24, 2014. Accepted in final form November 21, 2014.

\section{REFERENCES}

1. Centers for Disease Control and Prevention: Hepatitis C Information for Health Professionals (2014, July). Available at: http://www.cdc.gov/hepatitis/HCV/index.htm. Accessed January 2, 2014.

2. Fletcher NF, Yang JP, Farquhar MJ, et al. Hepatitis C virus infection of neuroepithelioma cell lines. Gastroenterology 2010;139:1365-1374.

3. Laskus T, Radkowski M, Bednarska A, et al. Detection and analysis of hepatitis $C$ virus sequences in cerebrospinal fluid. J Virol 2002;76:10064-10068.

4. Hilsabeck RC, Hassanein TI, Carlson MD, Ziegler EA, Perry W. Cognitive functioning and psychiatric symptomatology in patients with chronic hepatitis C. J Int Neuropsychol Soc 2003;9:847-854.

5. Hinkin $\mathrm{CH}$, Castellon SA, Levine AJ, Barclay TR, Singer EJ. Neurocognition in individuals co-infected with HIV and hepatitis C. J Addict Dis 2008;27:11-17.

6. Forton DM, Thomas HC, Murphy CA, et al. Hepatitis C and cognitive impairment in a cohort of patients with mild liver disease. Hepatology 2002;35:433-439.

7. Grover VP, Pavese N, Koh SB, et al. Cerebral microglial activation in patients with hepatitis $\mathrm{C}$ : in vivo evidence of neuroinflammation. J Viral Hepat 2012;19:89-96.

8. Weissenborn K, Krause J, Bokemeyer M, et al. Hepatitis C virus infection affects the brain-evidence from psychometric studies and magnetic resonance spectroscopy. J Hepatol 2004;41:845-851.

9. Bladowska J, Zimny A, Knysz B, et al. Evaluation of early cerebral metabolic, perfusion and microstructural changes 
in HCV-positive patients: a pilot study. J Hepatol 2013; 59:651-657.

10. Bladowska J, Zimny A, Kołtowska A, et al. Evaluation of metabolic changes within the normal appearing gray and white matters in neurologically asymptomatic HIV-1positive and $\mathrm{HCV}$-positive patients: magnetic resonance spectroscopy and immunologic correlation. Eur J Radiol 2013;82:686-692.

11. Forton DM, Allsop JM, Main J, Foster GR, Thomas HC, Taylor-Robinson SD. Evidence for a cerebral effect of the hepatitis C virus. Lancet 2001;358:38-39.

12. Forton DM, Hamilton G, Allsop JM, et al. Cerebral immune activation in chronic hepatitis $\mathrm{C}$ infection: a magnetic resonance spectroscopy study. J Hepatol 2008;49: 316-322.

13. Hilsabeck RC, Perry W, Hassanein TI. Neuropsychological impairment in patients with chronic hepatitis C. Hepatology 2002;35:440-446.

14. Ryan EL, Morgello S, Isaacs K, Naseer M, Gerits P. Neuropsychiatric impact of hepatitis $\mathrm{C}$ on advanced HIV. Neurology 2004;62:957-962.

15. Martin EM, Novak RM, Fendrich M, et al. Stroop performance in drug users classified by HIV and hepatitis $\mathrm{C}$ virus serostatus. J Int Neuropsychol Soc 2004;10:298-300.

16. Senzolo M, Schiff S, D’Aloiso CM, et al. Neuropsychological alterations in hepatitis $\mathrm{C}$ infection: the role of inflammation. World J Gastroenterol 2011;17:3369-3374.

17. McAndrews MP, Farcnik K, Carlen P, et al. Prevalence and significance of neurocognitive dysfunction in hepatitis $\mathrm{C}$ in the absence of correlated risk factors. Hepatology 2005;41:801-808.

18. Wechsler D. Wechsler Adult Intelligence Scale-Third Edition (WAIS-III), 3rd ed. San Antonio, TX: The Psychological Corporation; 1997.

19. Gronwall DM. Paced auditory serial-addition task: a measure of recovery from concussion. Percept Mot Skills 1977;44:367-373.

20. Partington JE, Leiter RG. Partington's pathway test. Psychol Serv Cent Bull 1949;1:9-20.

21. Stroop JR. Studies of interference in serial verbal reactions. J Exp Psychol 1935;18:643-662.

22. Brandt J, Benedict RHB. Hopkins Verbal Learning Test, Revised (HVLT-R). Odessa, FL: Psychological Assessment Resources; 1999.
23. Benedict RHB. Brief Visuospatial Memory Test-Revised (BVMT-R). Odessa, FL: Psychological Assessment Resources, Inc.; 1997.

24. Benton AL, Hamsher K, Sivan AB. Controlled oral word association test (COWAT). Multilingual Aphasia Examination, 3rd ed. Iowa City, IA: AJA Associates; 1983.

25. Matthews CJ, Kløve H. Instruction Manual for the Adult Neuropsychology Test Battery. Madison, WI: University of Wisconsin Medical School; 1964.

26. Lee KA, Hicks G, Nino-Murcia G. Validity and reliability of a scale to assess fatigue. Psychiatry Res 1991;36:291-298.

27. Chan T, Vese L. Active contours without edges. IEEE Trans Image Process 2001;10:266-277.

28. Gongvatana A, Cohen RA, Correia S, et al. Clinical contributors to cerebral white matter integrity in HIV-infected individuals. J Neurovirol 2011;17:477-486.

29. Stebbins GT, Smith CA, Bartt RE, et al. HIV-associated alterations in normal-appearing white matter: a voxel-wise diffusion tensor imaging study. J Acquir Immune Defic Syndr 2007;46:564-573.

30. Smith SA, Levante TO, Meier BH, Ernst RR. Computer simulations in magnetic resonance. An object-oriented programming approach. J Magn Reson Ser A 1994;106:75-105.

31. Benjamini Y, Hochberg Y. Controlling the false discovery rate: a practical and powerful approach to multiple testing. J R Stast Soc Series B 1995;54:289-300.

32. Douaud G, Behrens TE, Poupon C, et al. In vivo evidence for the selective subcortical degeneration in Huntington's disease. Neuroimage 2009;46:958-966.

33. Osuka S, Matsushita A, Ishikawa E, et al. Elevated diffusion anisotropy in gray matter and the degree of brain compression. J Neurosurg 2012;117:363-371.

34. Catani M, Dell'acqua F, Vergani F, et al. Short frontal lobe connections of the human brain. Cortex 2012;48: 273-291.

35. Nagarajan R, Sarma MK, Thames AD, Castellon SA, Hinkin $\mathrm{CH}$, Thomas MA. 2D MR spectroscopy combined with prior-knowledge fitting is sensitive to HCVassociated cerebral metabolic abnormalities. Int J Hepatol 2012;2012:179365.

36. Thames $\mathrm{AD}$, Foley JM, Wright MJ, et al. Basal ganglia structures differentially contribute to verbal fluency: evidence from Human Immunodeficiency Virus (HIV)-infected adults. Neuropsychologia 2012;50:390-395. 


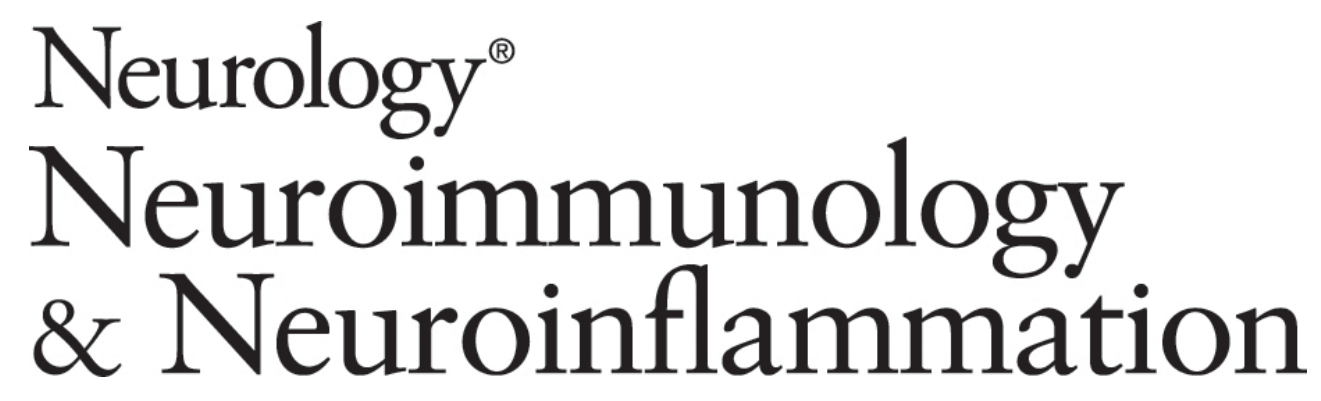

Neuroimaging abnormalities, neurocognitive function, and fatigue in patients with hepatitis C

April D. Thames, Steven A. Castellon, Elyse J. Singer, et al.

Neurol Neuroimmunol Neuroinflamm 2015;2;

DOI 10.1212/NXI.0000000000000059

This information is current as of January 14, 2015

Neurol Neuroimmunol Neuroinflamm is an official journal of the American Academy of Neurology.

Published since April 2014, it is an open-access, online-only, continuous publication journal. Copyright $($ ) 2015 American Academy of Neurology. All rights reserved. Online ISSN: 2332-7812.

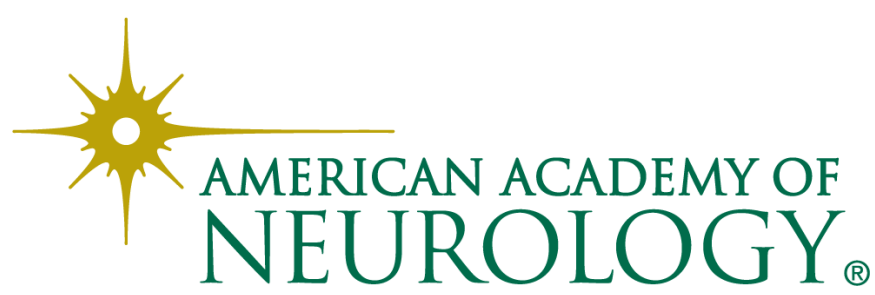




\section{Updated Information \&} Services

\section{Supplementary Material}

References

Subspecialty Collections

Permissions \& Licensing

Reprints including high resolution figures, can be found at: http://nn.neurology.org/content/2/1/e59.full.html

Supplementary material can be found at: http://nn.neurology.org/content/suppl/2015/01/14/2.1.e59.DC1

This article cites 30 articles, 1 of which you can access for free at: http://nn.neurology.org/content/2/1/e59.full.html\#\#ref-list-1

This article, along with others on similar topics, appears in the following collection(s):

\section{All Infections}

http://nn.neurology.org//cgi/collection/all_infections

Assessment of cognitive disorders/dementia

http://nn.neurology.org//cgi/collection/assessment_of_cognitive_disord ers_dementia

MR̄I

http://nn.neurology.org//cgi/collection/mri

Neuropsychological assessment

http://nn.neurology.org//cgi/collection/neuropsychological_assessment

Information about reproducing this article in parts (figures,tables) or in its entirety can be found online at:

http://nn.neurology.org/misc/about.xhtml\#permissions

Information about ordering reprints can be found online: http://nn.neurology.org/misc/addir.xhtml\#reprintsus

Neurol Neuroimmunol Neuroinflamm is an official journal of the American Academy of Neurology.

Published since April 2014, it is an open-access, online-only, continuous publication journal. Copyright $\odot$ 2015 American Academy of Neurology. All rights reserved. Online ISSN: 2332-7812.

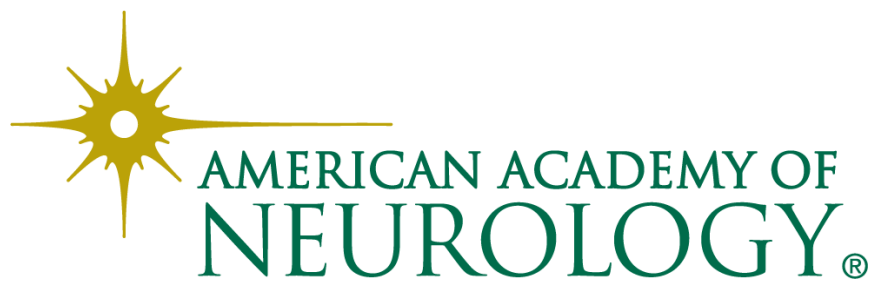

